www.jmscr.igmpublication.org

Impact Factor 5.84

Index Copernicus Value: 83.27

ISSN (e)-2347-176x ISSN (p) 2455-0450

crossref DOI: _https://dx.doi.org/10.18535/jmscr/v5i8.55

Journal Of Medical Science And Clinical Research

IGM Publication

An Official Publication of IGM Publication

\title{
Clinical Outcome of Induction Chemotherapy and Simultaneous Chemo Radiotherapy in Stage IIIA or IIIB Inoperable Non-Small Cell Lung Cancer
}

\author{
Authors
}

\section{Dr Preeya. V, Dr Devi Mohan}

Department of Radiation Oncology, Department of Community Medicine, Government Medical College,

Thiruvananthapuram

\begin{abstract}
Aims: Two meta-analyses have shown a survival advantage for the addition of concurrent chemotherapy to radiotherapy and other sequential radiochemotherapy in the treatment of inoperable advanced lung cancer. The aims of this study were to examine treatment outcomes (survival, time to progression, response rates and toxicity) in patients with lung cancer treated with sequential chemor adiation and to compare these with outcomes in patients treated with radiation alone.
\end{abstract}

Materials and Methods; Between December 2010 and November 2012, 138 patients of inoperable Stage 111A and Stage 111B Non small Cell lung cancer (NSCLC) were treated with chemoradiation.. Acute toxicity was recorded, with toxicity graded using the common toxicity criteria version4. The median age was 58 years. All patients were staged with computed tomography and brnchoscopy. After induction chemotherapy 68 patients were treated with radiation alone and 70 patients were treated concurrent chemo radiation. This was due to waiting list problems. The chemotherapy used was paclitaxel $60 \mathrm{mg} / \mathrm{m} 2$ weekly with radiotherapy, (the neo adjuvant dose was Paclitaxel 175 $\mathrm{mg} / \mathrm{m} 2$ with cisplatin $75 \mathrm{mg} / \mathrm{m} 23$ weekly). External beam radiotherapy was given to the chest (40 Gy/20 fractions/4 weeks) followed by 10 Gy boost in 5 fractions.

Results: Patients benefited to an extent of 3.6 months of median time to progression and 3.42 months of mean survival time without major increases in toxicity. The frequent toxicity in our study was Grade 1 Esophagitis followed by grade 1 pneumonitis

Conclusion: There was a trend towards improved survival with concurrent chemoradiation in this cohort of patients that may become significant with longer follow-up.

Keywords: Lung carcinoma, chemoradiotherapy, outcome, time to progression, survival, toxicity.

\section{Introduction}

${ }^{1}$ Lung cancer continue to be an important healthcare problem in India as well as globally. It remains as the most common cancer in the world since the last several decades, making up $12.7 \%$ of all new cancers in the world. Interestingly, incidence seems to be increasing in developing countries as well as females all over the world.

\section{IIIA inoperable}

For stage III A Concurrent chemo-RT (63 Gy) followed by adjuvant chemotherapy (LAMP,
RTOG 9410; French and Japanese) ${ }^{4,5,10}$. The 5year OS and median survival in concurrent chemo-RT is $20-25 \%$ \& $16-17$ months respectively. If unacceptable risk of pneumonitis with up front radiation, consider induction chemo for down-staging followed by concurrent chemoRT (to post-chemotherapy tumour volume) if no progression of disease. (CALGB 39801). ${ }^{9,12}$ Sequential chemo-RT: OS 20\%, median survival 13-15 months. RT alone the OS $<10 \%$ \& median survival is $10-12$ months.

IIIB (without pleural effusion) 
Concurrent chemo-RT (61-63 Gy) (LAMP, RTOG 9410$)^{4,5,10}$ is preferred. If unacceptable risk of pneumonitis with upfront RT, consider induction chemotherapy for down-staging and concurrent chemoradiation to post chemotherapy tumour volume, if no progression of disease occurs. (CALGB 39801).

\section{Radiotherapy}

Radiotherapy has an established role in management of lung cancer, both on its own and in combination with chemotherapy. Patients with $\mathrm{N} 2$ disease, chemo radiation is the treatment of choice. ${ }^{3}$.

${ }^{8}$ SWOG trial of preoperative chemo radiation showed an improvement in patient survival with acceptable toxicity profile in patients with Stage 111A disease. Maximum benefit in terms of PFS was seen in trimodality arm.

\section{Inoperable NSCLC:}

\section{Definitive Radiotherapy Stage 111}

Usually high doses of 60-75 $\mathrm{Gy}$ is required to sterilize all tumor cells. With conventional fractionation of $2 \mathrm{~Gy} / \mathrm{Fr} /$ day, a total dose of 60 $\mathrm{Gy}^{5,10}$ with acceptable toxicities has been considered standard. Because of tumor motion during radiation, IGRT plays an important role in the management of NSCLC.

Definitive Chemo radiotherapy CALBG trial, RTOG $9410^{13}$ trial showed that Median and 5 year survival were superior for chemo radiation arm. On the basis of these results, concurrent chemo radiation has become the standard of care for inoperable and unresectable NSCLC.

Radiation Toxicity: Lung toxicity $-{ }^{18}$ Radiation pneumonitis peaks at 2 months after completion of radiotherapy. It is stabilized or resolved around 612 months. It is usually treated with corticosteroids. Lung fibrosis occurs usually a few months after radiation and tends to become chronic. It is seen that a mean lung dose of around $20 \mathrm{~Gy}$ is associated with $24 \%$ grade 2 and above pneumonitis..

Esophageal toxicity: ${ }^{11}$ occurs 2 to 3 weeks after start of radiation. Patient usually complaints of dysphagia and odynophagia which worsens towards the end of treatment. This acute reaction of radiation usually peaks during the completion of first week of Radiotherapy and is responsible for significant morbidity because of dehydration and weight loss. The late reactions seen are strictures and perforation. In general, tolerance of esophagus is around $60 \mathrm{~Gy}$.

\section{Materials and Methods}

The study was conducted in the Department of Radiotherapy, Medical College, Trivandrum. Human ethical committee clearance was obtained for this study. The participants of this study consist of 138 patients of inoperable Stage 111A and Stage 111B Non small Cell lung cancer (NSCLC). All patients have undergone treatment protocol followed in our department. All these patients attended the OP clinic of the department of Radiotherapy.

Patients between the ages of 18-75 yrs, with performance status 0-2, histologically confirmed NSCLC, inoperable and with no previous chemotherapy and radiotherapy were included in the study. Patients had to present with an assessable stage $111 \mathrm{~B}$ or inoperable stage 111A, based on computed tomography and bronchoscopy.

At study entry, all patients were required to be present adequate physiologic, hematologic, renal and, hepatic function, as well as uncompromised respiratory function. The study is a comparative observational study of the assigned treatment received by the patient's of stage $111 \mathrm{~A}$ and stage $111 \mathrm{~B}$ in our department. Before inclusion in the study, all patients provided written informed consent

Two cycles of induction chemotherapy were administered to all patients. Paclitaxel $175 \mathrm{mg} / \mathrm{m}^{2}$ was infused over 3 hours, followed by Cisplatin $75 \mathrm{mg} / \mathrm{m}^{2}$ as one hour infusion with adequate hydration. Patients received intravenous premedication with Ranitidine $50 \mathrm{mg}$, Dexamethasone $8 \mathrm{mg}$ on the previous day. These two drugs along with Chlorpheniramine $25 \mathrm{mg}$ and Ondansetron $8 \mathrm{mg}$ was given thirty minutes prior to administration of Paclitaxel. Treatment 
was stopped and patients went off study in case of insufficient hematologic recovery, significant hypersensitivity to Paclitaxel or cardiac decompensation. After two cycles, patients were restaged and those showing progressive disease went off study. Patients with a good response were reevaluated for operability and if found operable they left the study i.e.; one among lost follow up. Every consecutive patient assigned to above said protocols in the OPD were assigned as study sample under that particular treatment arm. Patient is then taken to the Department of Radio diagnosis where a diagnostic CT scan unit is available. Patient lie supine with arms extended above head and field centers are aligned using lasers. fiducial markers are placed in the midline and at two lateral points where lasers meet 0.5 mm cut CT slices are taken from chin to upper third of abdomen.

Data like patient's anatomical information and fiducial marker points are collected in a CD in DICOM format and CT scan data is transferred to the treatment planning system 'CMS $\mathrm{XiO}^{\prime}$ in our department. Primary tumor and enlarged lymph nodes ( $>1.5 \mathrm{~cm}$ transverse diameter) are contoured which forms the gross tumor volume (GTV). Clinical target volume (CTV) typically includes the GTV plus $1-1.5 \mathrm{~cm}$ margin. Planning target volume (PTV) add $0.5-1.5 \mathrm{~cm}$ margin on CTV to account for set-up uncertainties and respiratory motion. Spinal canal, normal lung (lung volumePTV), heart are the organ at risk which are contoured

\section{GTV-red, PTV-white, blue color wash out}

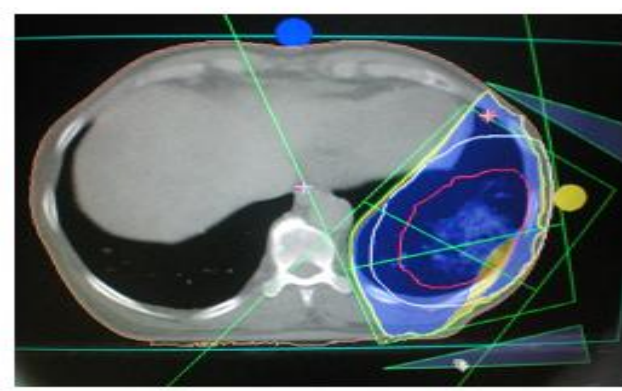

GTV +PTV for boost

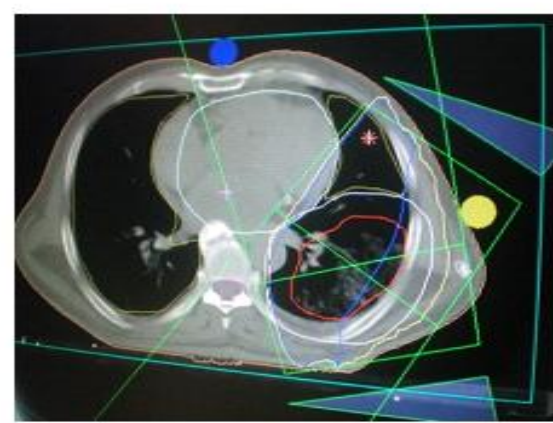

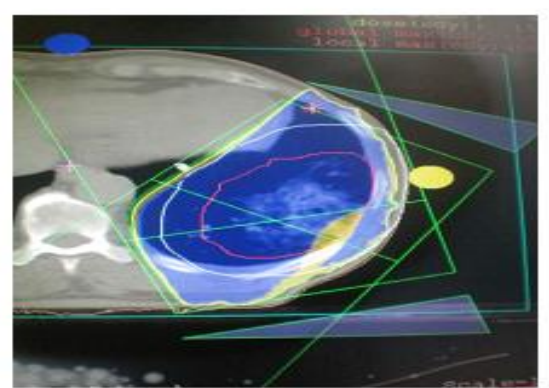

Beam's eye view

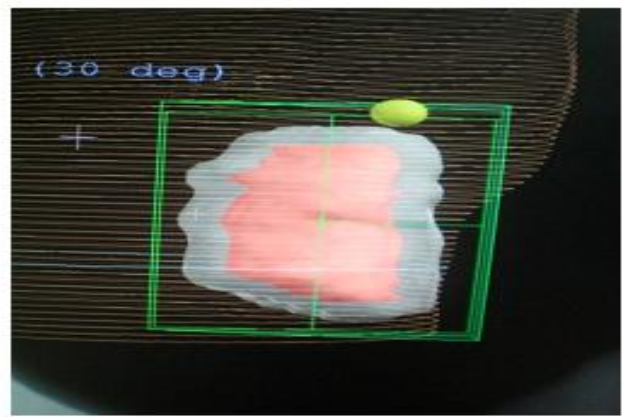

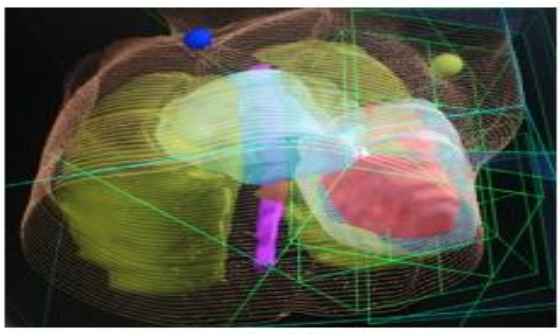

OAR

Fig. 24 
Patients were to receive 40 Gy to the primary tumor and mediastinum with antero-posterior opposed field, followed by a boost of 10 Gy to macroscopic disease through multifield technique/as condition warrants .Even though a 3D planning is done, it is our institutional policy to limit the dose to $50 \mathrm{~Gy}$, because conformal treatment with multi leaf collimator (Standard dose is 60Gy) is not available in our department. The treatment was delivered by Theratron Equinox Co- 60 machine with conventional schedule of $2 \mathrm{~Gy} /$ fraction, 5days a week for 25 days or 5 weeks. The supraclavicular area was irradiated in case of enlarged upper mediastinal nodes. Total dose of spinal canal was kept to less than $45 \mathrm{~Gy}$, mean lung dose is kept below $20 \mathrm{~Gy}$, V20 less than $20 \%$ and heart less than 40 Gy for $50 \%$ volume and DVH (Dose volume histogram) is plotted.
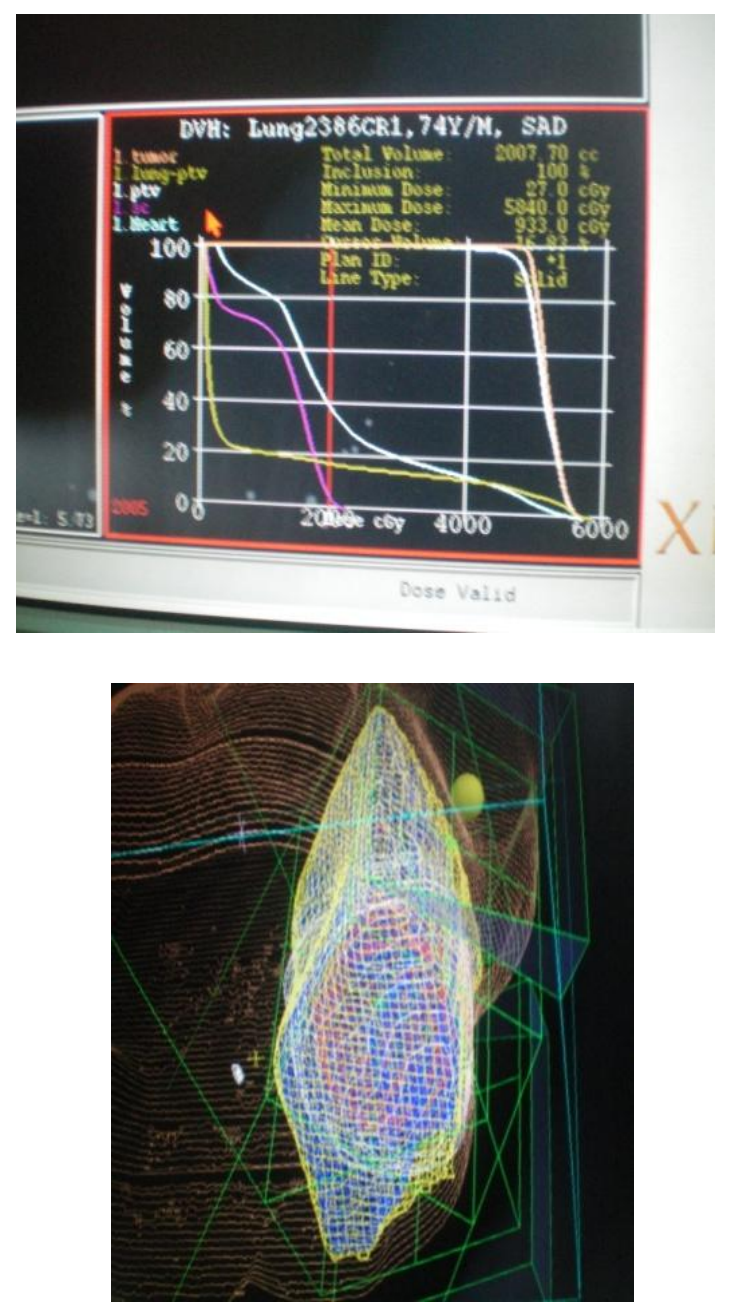

Fig. 25
Patient in chemo radiotherapy group received 1 hour infusion of Paclitaxel $60 \mathrm{mg} / \mathrm{m}^{2}$ in weekly intervals over 5 weeks, up to six hours before radiotherapy, starting on day 1 of radiotherapy. Patients received premedication as during induction therapy. Paclitaxel was delayed by one week in case of insufficient hematological recovery.

Patient who has completed the two assigned treatment protocol are advised to report after four to five weeks and continued with maintenance chemotherapy for 4 more cycles with the same drugs as used for induction chemotherapy, dose of which is sometimes compromised considering the performance status of the patient.

Response was assessed by imaging methods, 3 months after the end of therapy using RECIST (response evaluation criteria in solid tumors) as complete response (CR), partial response (PR), stable disease (SD), progressive disease (PD). Adverse events and toxicities were graded. All observed toxicities were recorded. Hematologic parameters were observed weekly, and blood chemistry parameters and clinical and neurological examination results were obtained before every chemotherapy cycle and after end of therapy. A chest x-ray for detection of radiation pneumonitis was performed 4 weeks after the end of radiotherapy. The observed data regarding response to treatment, toxicities, overall survival and time to progression of the two treatment arms were entered and analyzed using SPSS software with the help of a medical statistician of Preventive medicine Department of Medical College, Thiruvananthapuram. A P- Value of $<0.05$ is considered significant.

\section{Observations and Results \\ Patient and tumour characteristics}

138 patients with inoperable Stage 111A and Stage 111 B non-small cell lung cancer were included in the study. 11 patients went off the study due to non-compliance to treatment, progression while on radiotherapy or chemo radiotherapy and various others causes. They had the following characteristics: 
The median age of the patients in our study is 58 and chemo radiotherapy arm it was $58.14 \mathrm{yrs}$ yrs. In the radiation alone arm it was 58.10 yrs.

\begin{tabular}{|l|c|c|c|c|c|c|}
\hline Parameters & Number & Percentage & \multicolumn{2}{|c|}{$\begin{array}{c}\text { Radiotherapy } \\
\text { alone arm }\end{array}$} & $\begin{array}{c}\text { Chemo radiation } \\
\text { arm }\end{array}$ \\
\hline Sex & \multicolumn{5}{|l|}{} \\
\hline Male & 120 & $87 \%$ & 60 & $85.7 \%$ & 60 & $87 \%$ \\
\hline Female & 18 & $13 \%$ & 8 & 14.35 & 10 & $13 \%$ \\
\hline Performance status & & & & & \\
\hline 1 & 29 & $21 \%$ & 15 & $22.1 \%$ & 14 & $20 \%$ \\
\hline 2 & 109 & $79 \%$ & 53 & $77.9 \%$ & 56 & $79 \%$ \\
\hline Stage IIIA & 32 & $23.2 \%$ & 16 & $23.5 \%$ & 16 & $22.9 \%$ \\
Stage IIIB & 106 & $76.8 \%$ & 52 & $76.5 \%$ & 54 & $77.1 \%$ \\
\hline Adenocarcinoma & $36.2 \%$ & 20 & $29.4 \%$ & 30 & $42.9 \%$ \\
Squamous cell & $29 \%$ & 21 & $30.9 \%$ & 19 & $27.9 \%$ \\
Large cell & $0.7 \%$ & 1 & $1.5 \%$ & 0 & $0 \%$ \\
unspecified & $21 \%$ & 13 & $19.1 \%$ & 16 & $22.9 \%$ \\
Unclassified & $12.3 \%$ & 13 & $19.1 \%$ & 4 & $5.7 \%$ \\
\hline
\end{tabular}

Adenocarcinoma histology is more frequent type in this study followed by squamous cell carcinoma. Next in frequency in our study population is poorly differentiated carcinoma which is grouped as non-classified [NC]. The proportion of patients with each of the above mentioned histology is almost similar in two treatment groups.

Fig. 25 Histological types of patients in the study population

RT ALONE

TREALARM

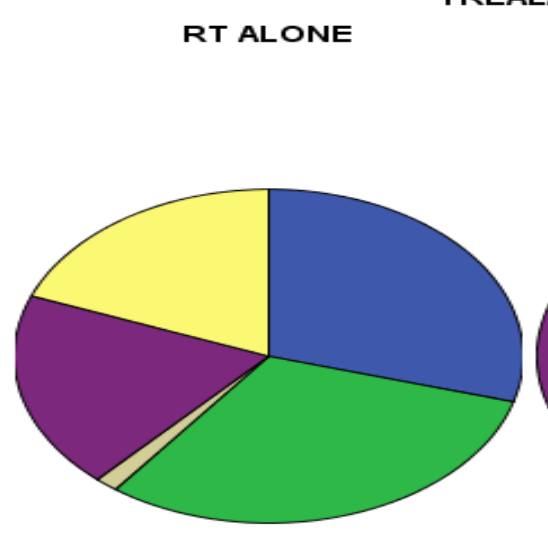

CHEMORADIATION

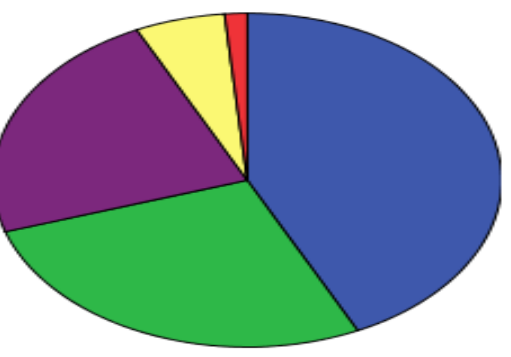

\section{Distribution of patients in the two arms}

\begin{tabular}{|c|c|c|c|c|c|}
\hline & & & TREATI & T ARM & Total \\
\hline & & & $\begin{array}{l}\text { RT } \\
\text { ALONE }\end{array}$ & $\begin{array}{l}\text { CHEMORADI } \\
\text { ATION }\end{array}$ & \\
\hline STAGE & III A & Count & 16 & 16 & 32 \\
\hline & & $\%$ within TREALARM & $23.5 \%$ & $22.9 \%$ & $23.2 \%$ \\
\hline & III B & Count & 52 & 54 & 106 \\
\hline & & $\%$ within TREALARM & $76.5 \%$ & $77.1 \%$ & $76.8 \%$ \\
\hline Total & & Count & 68 & 70 & 138 \\
\hline & & $\%$ within TREALARM & $100.0 \%$ & $100.0 \%$ & $100.0 \%$ \\
\hline
\end{tabular}

Majority of patients (approx 77\%) included in the study group was Stage 111B in the two treatment arms. 


\section{JMSCR Vol||05||Issue||08||Page 26312-26323||August}

Fig. 26 PIE-CHART OF PATIENTS SHOWING STAGE-WISE PROPOTION

TREALARM

CHEMORADIATION

STAGE
ᄆIIIIA
口III B

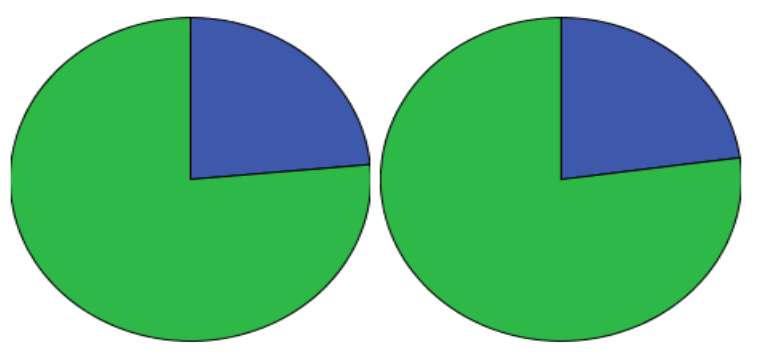

\section{3) Response evaluation}

After completion of treatment, response evaluation 3 months after the end of treatment is:

\begin{tabular}{|c|c|c|c|c|c|c|c|}
\hline & \multicolumn{5}{|c|}{ Response } & \multirow[t]{2}{*}{ Total } \\
\hline & & $\begin{array}{c}\mathrm{CR} \\
\text { (complete) }\end{array}$ & $\begin{array}{c}\text { Partial } \\
\text { (PR) }\end{array}$ & $\begin{array}{l}\text { Stable } \\
\text { (SD) }\end{array}$ & Progression & LFU & \\
\hline $\begin{array}{l}\text { Treat } \\
\text { arm }\end{array}$ & $\begin{array}{c}\text { RT alone count } \\
\%\end{array}$ & $\begin{array}{c}11 \\
16.2 \%\end{array}$ & $\begin{array}{c}34 \\
50 \%\end{array}$ & $\begin{array}{c}7 \\
10.3 \% \\
\end{array}$ & $\begin{array}{c}10 \\
14.7 \%\end{array}$ & $\begin{array}{c}6 \\
8.6 \%\end{array}$ & $\begin{array}{c}68 \\
100 \%\end{array}$ \\
\hline & $\begin{array}{c}\text { Chemo RT count } \\
\%\end{array}$ & $\begin{array}{c}14 \\
20.0 \% \\
\end{array}$ & $\begin{array}{c}42 \\
60.0 \% \\
\end{array}$ & $\begin{array}{c}1 \\
1.4 \% \\
\end{array}$ & $\begin{array}{c}8 \\
11.4 \% \\
\end{array}$ & $\begin{array}{c}5 \\
7.1 \% \\
\end{array}$ & $\begin{array}{c}70 \\
100 \% \\
\end{array}$ \\
\hline Total & $\begin{array}{c}\text { Count } \\
\%\end{array}$ & $\begin{array}{c}25 \\
18.1 \%\end{array}$ & $\begin{array}{c}76 \\
55.1 \%\end{array}$ & $\begin{array}{c}8 \\
5.8 \%\end{array}$ & $\begin{array}{c}18 \\
13.0 \%\end{array}$ & $\begin{array}{c}11 \\
8.0 \%\end{array}$ & $\begin{array}{c}138 \\
100 \%\end{array}$ \\
\hline
\end{tabular}

Majority of patients are having a partial response [50\% in RT alone arm and 60\% in chemo radiotherapy arm .Responses are better in chemo radiotherapy arm than radiotherapy alone arm. Patients who showed progression are $14.7 \%$ in
Radiotherapy alone arm and $11.4 \%$ in Chemo radiotherapy arm. Patients with stable disease are more in radiotherapy alone arm $(10.3 \%)$ and Chemo radiotherapy arm it is only $1.4 \%$

Fig. 27 Bar diagram showing response to two treatment arms
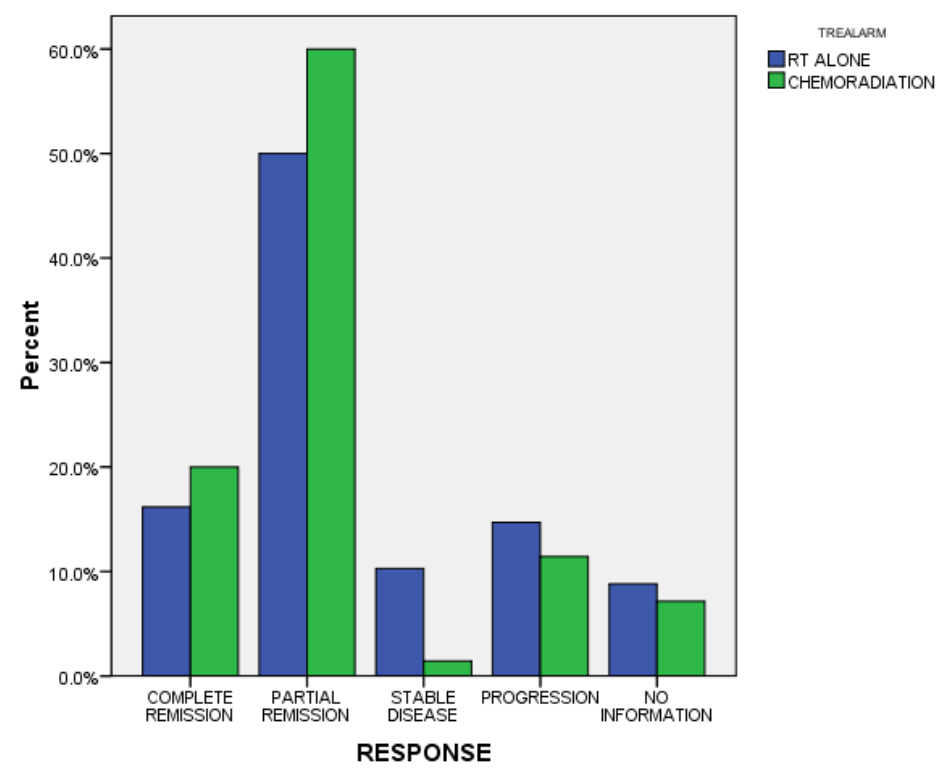
4) Patients who progressed during study period [2 years]

\begin{tabular}{|c|c|c|c|c|c|}
\hline \multicolumn{6}{|l|}{ Crosstab } \\
\hline & & & \multicolumn{2}{|c|}{ Progression } & \multirow[t]{2}{*}{ Total } \\
\hline & & & Progression & $\begin{array}{c}\text { No } \\
\text { progression }\end{array}$ & \\
\hline \multirow{4}{*}{$\begin{array}{l}\text { TREAT } \\
\text { ARM }\end{array}$} & \multirow[t]{2}{*}{ RT ALONE } & Count & 56 & 6 & 62 \\
\hline & & $\%$ within TREAT ARM & $90.3 \%$ & $9.7 \%$ & $100.0 \%$ \\
\hline & \multirow[t]{2}{*}{ CHEMOR/T } & Count & 64 & 1 & 65 \\
\hline & & $\%$ within TREAT ARM & $98.5 \%$ & $1.5 \%$ & $100.0 \%$ \\
\hline & \multirow[t]{2}{*}{ Total } & Count & 120 & 7 & 127 \\
\hline & & $\%$ within TREAT ARM & $94.5 \%$ & $5.5 \%$ & $100.0 \%$ \\
\hline
\end{tabular}

\begin{tabular}{|c|c|c|c|c|c|}
\hline \multicolumn{6}{|l|}{ Chi-Square Tests } \\
\hline & Value & $\mathrm{df}$ & $\begin{array}{l}\text { Asymp. Sig. } \\
\text { (2-sided) }\end{array}$ & $\begin{array}{l}\text { Exact Sig. } \\
\text { (2-sided) }\end{array}$ & $\begin{array}{l}\text { Exact Sig. (1- } \\
\text { sided) }\end{array}$ \\
\hline Pearson Chi-Square & $4.036^{\mathrm{a}}$ & $\overline{1}$ & .045 & & \\
\hline Continuity Correction $^{\mathrm{b}}$ & 2.625 & 1 & .105 & & \\
\hline Likelihood Ratio & 4.425 & 1 & .035 & & \\
\hline Fisher's Exact Test & & & & .058 & .050 \\
\hline $\begin{array}{l}\text { Linear-by-Linear } \\
\text { Association }\end{array}$ & 4.004 & 1 & .045 & & \\
\hline $\mathrm{N}$ of Valid Cases ${ }^{\mathrm{b}}$ & 127 & & & & \\
\hline \multicolumn{6}{|c|}{ a. 2 cells $(50.0 \%)$ have expected count less than 5 . The minimum expected count is 3.42 . } \\
\hline b. Computed only for a & able & & & & \\
\hline
\end{tabular}

$\mathrm{P}$ value is 0.105 , which is not significant. Hence, even though number of patients who progressed during the study period was more for chemo- radiotherapy arm, since $p$ value is $>0.05$, is not statistically significant and this is attributed to error in assignment.

\begin{tabular}{|l|c|c|c|c|c|}
\hline Crosstab & & & \multicolumn{3}{|c|}{} \\
\hline & & & \multicolumn{2}{|c|}{ Death } & \multirow{2}{*}{ Total } \\
\hline & & & Death & Alive & \\
\hline \multirow{3}{*}{ TREALARM } & \multirow{2}{*}{ RT ALONE } & Count & 52 & 10 & 62 \\
\cline { 3 - 6 } & & $\%$ within TREALARM & $83.9 \%$ & $16.1 \%$ & $100.0 \%$ \\
\cline { 3 - 6 } & \multirow{2}{*}{ CHEMORADIATION } & Count & 57 & 8 & 65 \\
\cline { 3 - 6 } & & $\%$ within TREALARM & $87.7 \%$ & $12.3 \%$ & $100.0 \%$ \\
\hline \multirow{2}{*}{ Total } & Count & 109 & 18 & 127 \\
\cline { 3 - 6 } & & $\%$ within TREALARM & $85.8 \%$ & $14.2 \%$ & $100.0 \%$ \\
\hline
\end{tabular}

\begin{tabular}{|c|c|c|c|c|c|}
\hline \multicolumn{6}{|l|}{ Chi-Square Tests } \\
\hline & Value & $\overline{\mathrm{df}}$ & $\begin{array}{c}\text { Asymp. Sig. } \\
\text { (2-sided) }\end{array}$ & $\begin{array}{l}\text { Exact Sig. } \\
\text { (2-sided) }\end{array}$ & $\begin{array}{c}\text { Exact Sig. } \\
\text { (1-sided) }\end{array}$ \\
\hline Pearson Chi-Square & $.381^{\mathrm{a}}$ & 1 & .537 & & \\
\hline Continuity Correction ${ }^{b}$ & .132 & 1 & .717 & & \\
\hline Likelihood Ratio & .381 & 1 & .537 & & \\
\hline Fisher's Exact Test & & & & .615 & .358 \\
\hline Linear-by-Linear Association & .378 & 1 & .539 & & \\
\hline $\mathrm{N}$ of Valid Cases ${ }^{b}$ & 127 & & & & \\
\hline \multicolumn{6}{|c|}{ a. 0 cells $(.0 \%)$ have expected count less than 5 . The minimum expected count is 8.79 . } \\
\hline b. Computed only for a $2 \times 2 \mathrm{tal}$ & & & & & \\
\hline
\end{tabular}

Death is slightly more in chemo radiotherapy arm which is not statistically significant as $p$ value is 0.537.Even though the number of patients who have progressed and died during study period are more in chemo radiotherapy arm, there is no difference in proportion of progression and death of patients between two treatment arms ( $\mathrm{P}$ value not $<0.05$ ) 


\section{5) Time to progression}

Time to progression was calculated from time of random assignment until documented progression. Median time to progression is 7 months for radiotherapy alone arm and 10 months for chemoradiation arm, when analyzed for 56 patients who have progressed in radiotherapy arm and 64 patients who have progressed in chemoradiation arm . P-value is 0.000 which is highly significant, which favours chemo radiotherapy.

\begin{tabular}{|l|c|c|c|c|c|}
\hline Group Statistics & $\begin{array}{c}\text { TREATMENT } \\
\text { ARM }\end{array}$ & $\mathrm{N}$ & Mean & $\begin{array}{c}\text { Std. } \\
\text { Deviation }\end{array}$ & Std. Error Mean \\
\hline TIME & RT ALONE & 56 & 7.00 & 3.063 & .409 \\
\cline { 2 - 7 } TOPROGENISIS & CHEMOR/T & 64 & 10.36 & 4.255 & .532 \\
\hline
\end{tabular}

\section{6) Survival Analysis}

Data are presented using Kaplan-Meier life table method. Time to progression showed a

Fig. 28 Kaplan-Meier for time to progression statistically significant difference in favor of chemo radiation.

\section{Survival Functions}
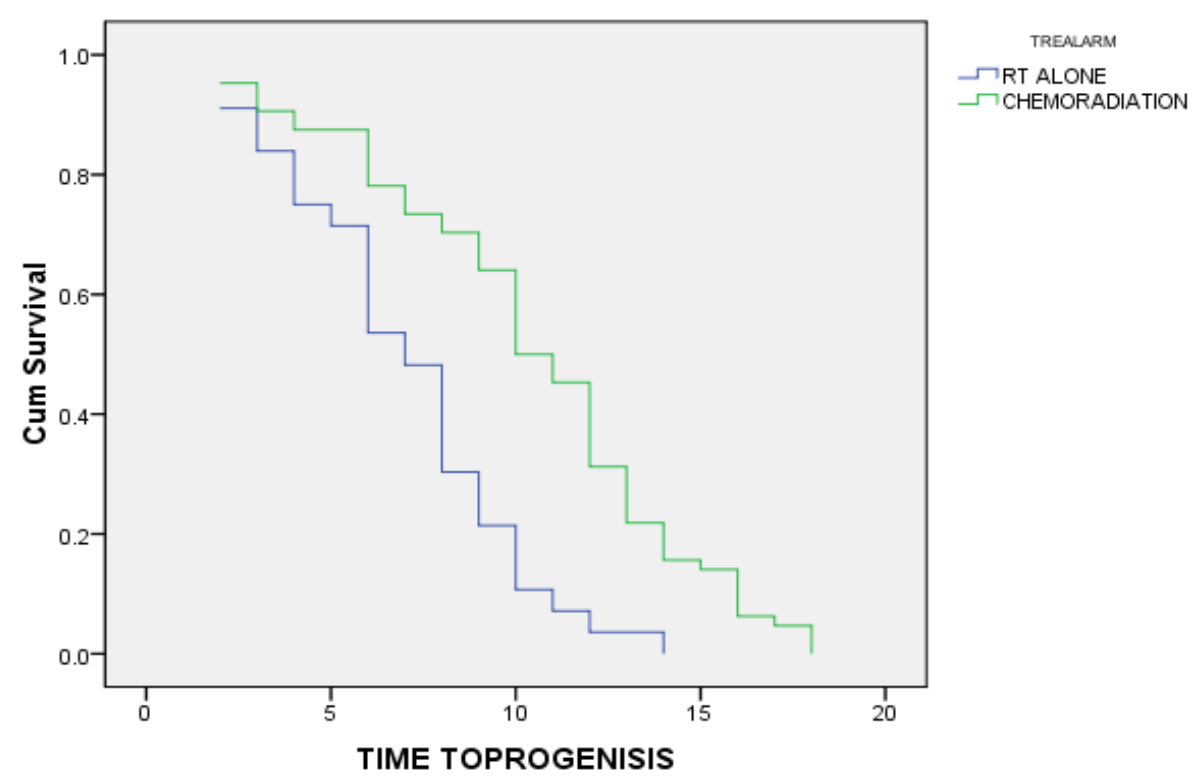

Overall survival Group Statistics

\begin{tabular}{|c|c|c|c|c|c|}
\hline & $\begin{array}{c}\text { TREATMENT } \\
\text { ARM }\end{array}$ & $\mathrm{N}$ & Mean & $\begin{array}{c}\text { Std. } \\
\text { Deviation }\end{array}$ & $\begin{array}{c}\text { Std. Error } \\
\text { Mean }\end{array}$ \\
\hline \multirow{2}{*}{$\begin{array}{l}\text { OVERALL } \\
\text { SURVIVAL }\end{array}$} & RT ALONE & 62 & 9.26 & 2.764 & .351 \\
\hline & CHEMOR/T & 65 & 12.88 & 4.505 & .559 \\
\hline
\end{tabular}

\begin{tabular}{|l|l|l|l|}
\hline Overall Comparisons & Chi-Square & df & Sig. \\
\hline Log Rank (Mantel-Cox) & 30.421 & 1 & .000 \\
\hline $\begin{array}{l}\text { Test of equality of survival distributions for the different levels of } \\
\text { treatment arms. }\end{array}$ \\
\hline
\end{tabular}

By $\mathrm{t}$ - test and log Rank test, $\mathrm{p}$ value is 0.000 , so difference of overall survival between two treatment arms are significant. Overall Survival is superior in Chemo-radiotherapy arm. 
Fig. 29 Over all survival curve

Survival Functions

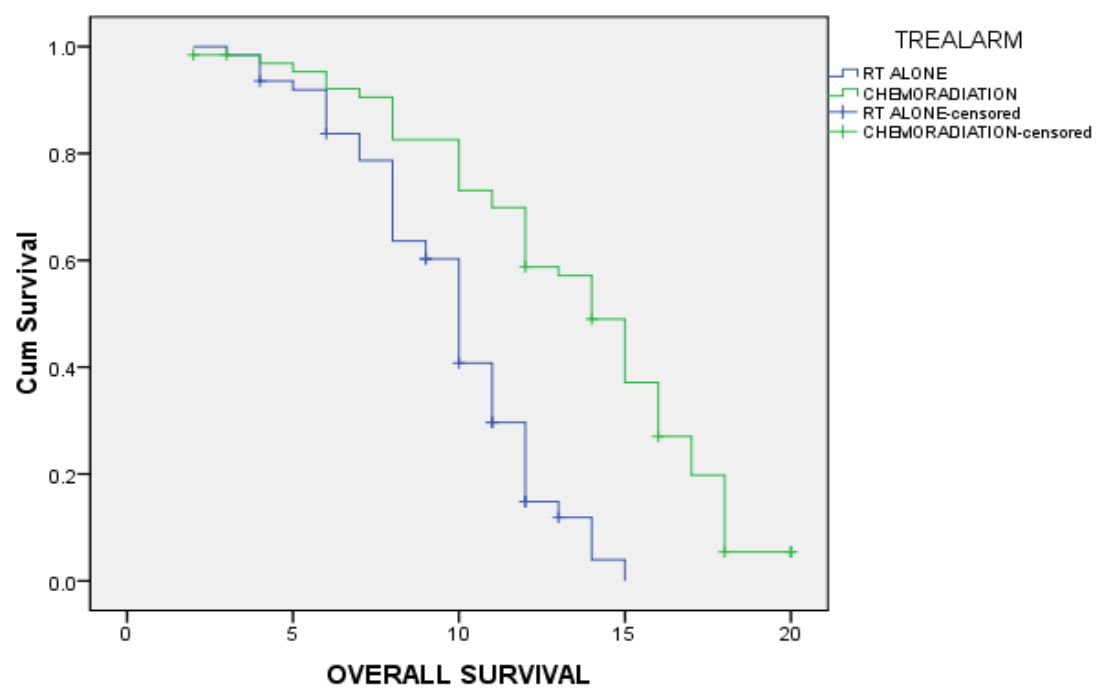

\begin{tabular}{|l|l|l|l|}
\hline Overall Comparisons & Chi-Square & df & Sig. \\
\hline Log Rank (Mantel-Cox) & 27.729 & 1 & .000 \\
\hline Test of equality of survival distributions for the different levels of \\
TREATMENT ARM.
\end{tabular}

Overall survivals were measured from the time of assignment until death or last follow up. Data are presented using Kaplan-Meier curve and difference tested by log-rank test. Mean survival time is 9 months in radiation alone arm and 12 months in chemoradiation arm. The difference was statistically significant with a p-value of 0.000 , in favour of chemoradiation.

\section{7) Toxicity}

Induction chemotherapy was well tolerated, with $2.1 \%$ patients with grade3 nausea and vomiting and $3.8 \%$ of patients with grade $3 \& 4$ leucopenia .Toxicities during radiotherapy alone and chemo radiotherapy were as follows: Grade 1 esophagitis was the most frequent side effect. However, overall toxicity was not statistically different between the 2 groups.

\begin{tabular}{|l|c|c|c|c|}
\hline Toxicity & RT alone-no. & RT alone $\%$ & $\begin{array}{c}\text { Chemo-RT, } \\
\text { No. }\end{array}$ & chemoRT\% \\
\hline Grade 1 pneumonitis & 12 & $19.4 \%$ & 13 & $20 \%$ \\
\hline Grade2 pneumonitis & 11 & $17.7 \%$ & 9 & $13.8 \%$ \\
\hline Grade 3 pneumonitis & 2 & $3.2 \%$ & 2 & $3.1 \%$ \\
\hline Grade 1 esophagitis & 24 & $38.7 \%$ & 25 & $38.5 \%$ \\
\hline Grade 2 esophagitis & 1 & $1.6 \%$ & 3 & $4.6 \%$ \\
\hline Leucopenia & 7 & $11.3 \%$ & 8 & $12.3 \%$ \\
\hline Nausea & 9 & $14.5 \%$ & 18 & $27.7 \%$ \\
\hline Anemia & 6 & $9.7 \%$ & 5 & $7.7 \%$ \\
\hline Cough & 2 & $3.2 \%$ & 2 & $3.1 \%$ \\
\hline Fatigue & 2 & $3.2 \%$ & 7 & $10.8 \%$ \\
\hline Hemoptysis & 1 & $1.6 \%$ & 2 & $3.1 \%$ \\
\hline Fever & 4 & $6.5 \%$ & 3 & $4.6 \%$ \\
\hline Chest pain & 8 & $12.9 \%$ & 8 & $12.3 \%$ \\
\hline Neutropenia & 0 & $0 \%$ & 3 & $4.6 \%$ \\
\hline Peripheral neuritis & 2 & $3.2 \%$ & 3 & $4.6 \%$ \\
\hline Mucositis & 1 & $1.6 \%$ & 3 & $4.6 \%$ \\
\hline Diarrhea & 2 & $3.2 \%$ & 1 & $1.5 \%$ \\
\hline Hair loss & 9 & $14.5 \%$ & 15 & $23.1 \%$ \\
\hline
\end{tabular}




\section{Discussion}

In this study all patients after induction chemotherapy was selected in either Radiotherapy alone arm or Chemo radiotherapy arm. In the chemo radiotherapy arm where weekly paclitaxel $^{15,16}$ was given, showed superior results. The difference was statistically significant for time to progression and Overall Survival $(\mathrm{P}=0.000)$.

Induction chemotherapy with platinum containing regimens has shown to increase survival in inoperable Stage 111 NSCLC patients compared with radiotherapy alone. ${ }^{12} \mathrm{~A}$ mean survival time of 12 months with 50 Gy in our study is almost near to the survival time (14 months) of trials using induction chemotherapy with Cisplatin and Vinblastine followed by radiotherapy with 60 $\mathrm{Gy}^{13}$. Because the toxicity of this approach was low, trials were started that incorporated single agent chemotherapy concurrent with radiotherapy after the two cycles of induction chemotherapy. Weekly schedules were preferred as a compromise between possible radio sensitization and feasibility. CALBG 9130 trial studied radiotherapy 63 Gy alone versus radiotherapy plus Carboplatin weekly after two cycles of cisplatin and Vinblastine. Survival was identical in both groups, with a median survival time of 13 months and a three year survival rate of $20 \%{ }^{13,14}$ This result was confirmed by French trial that used daily carboplatin concurrent with radiotherapy after induction chemotherapy with Cisplatin/ Vinorelbine $^{14}$.

Radiotherapy sensitizer properties of paclitaxel have been shown in vitro. ${ }^{15,16}$ CALBG 39801 randomly assigned patients to two cycles of induction chemotherapy followed by weekly paclitaxel $(50 \mathrm{mg} / \mathrm{m} 2)$ and carboplatin AUC 2 concurrent with radiotherapy 66 Gy versus concurrent chemo radiotherapy only. ${ }^{12-14}$ In this study the median survival was 14 months and 3 year survival rate was $19 \%$ in both arms.

In our study, patients benefited to an extent of 3.6 months of median time to progression and 3.42 months of mean survival time without major increases in toxicity. The frequent toxicity in our study was Grade 1 Esophagitis followed by grade 1 pneumonitis. No dose limiting effects for bone marrow toxicity. There is no increase in pneumonitis or oesophagitis compared to other trials $^{11,18}$.

Another finding is that, only those patients responding to induction chemotherapy had a significant benefit from weekly concurrent chemo radiotherapy. Besides, induction chemotherapy may spare patients from intensive treatment who will experience early treatment failure. Compared to similar study ${ }^{17}$ CTRT99/97 by the Bronchial Carcinoma therapy group with a median survival time of 18.7 months and improvement of 3 year survival of $29.7 \%$, the result of our study did not yield an appreciable improvement in the above said factors. This may be due to less total dose of thoracic RT delivered which in turn affects local control and thereby less time to progression. Besides there was a higher portion of patients with Stage 111 B and ECOG performance status 2.

After completion of the of two treatment arms, all our patients received four cycles of consolidation chemotherapy or maintenance chemotherapy ${ }^{20}$ with same agents used in the induction chemotherapy. Consolidation chemotherapy was initiated only four to five weeks after completion of radiation. This duration allowed the patient to overcome the acute effects of the already received treatment. Maintenance chemotherapy is initiated with a thought that it may add some benefit to less than the standard dose of RT (60Gy) that we administered.

Marginal superiority of chemo radiotherapy followed by consolidation chemotherapy was supported by data from South West Oncology Group 9504 trial, which administered three courses of Docetaxel after full dose concurrent chemo radiotherapy with Vinblastine and cisplatin. $^{8,20}$

${ }^{19}$ Belani et al in 2003 concluded that, although the results with maintainance Paclitaxel was provocative, but in view of small sample size it is difficult to draw definitive conclusions, although this study did introduce the concept of maintenance chemotherapy. Median Progression 
free survival was 9.5 months and median overall survival was 18.75 months.

PARAMOUNT data in ASCO 2011, presented the use of Pemetrexed as maintenance therapy after the use of the same with platinum in induction for non squamous histology. This when compared to the patients receiving placebo. Placebo patients showed deterioration of general condition due to disease progression ${ }^{74}$ However choice and duration of maintenance treatment remains largely empirical and needs to be explained and discussed with each patient in terms of current trials.

\section{Conclusions}

Induction chemotherapy remains an option for patients with locally advanced Non small cell lung cancer who may initially be thought not to be candidates for intensive chemo-radiotherapy. Patients with reasonable performance status, showing response to the initial induction chemotherapy could receive weekly chemotherapy concomitant with radiotherapy as a viable treatment option.

Tumour response, time to progression, survival, all these parameters favour chemo-radiotherapy compared with radiotherapy alone.

Overall toxicity was not statistically significant between the two treatment groups. All the toxicities were tolerable. Toxicities of chemoradiotherapy could be reduced further with the use of newer imaging modalities like FDG PET and use of newer radiotherapy techniques like 3DCRT, IMRT and IGRT, thereby increasing quality of life of the advanced lung cancer. Recent studies also demonstrate the superiority of maintainace therapy in terms of 5 year survival. To conclude, all these combination treatment modalities judiciously utilized for the best favourable outcome with less toxicity.

\section{References}

1. Pathak AK, Bhutani M, Mohan A, Guleria $\mathrm{R}$, Bal S \&Kochupillai V. Ind J Chest Diseases Allied Sciences 2004; 46: 191203.
2. Gandara DR, Chansky K, Albain KS, et al: Consolidation docetaxel after concurrent chemoradiotherapy in stage IIIB nonsmall-cell lung cancer: Phase II Southwest Oncology Group Study S9504.J ClinOncol 21:2004-2010, 2003

3. NCCN guidelines(2012) for management of NSCLC

4. Fairlamb D et al.:A randomized comparison of radical radiotherapy with or without chemotherapy for patients with non-small cell lung cancer: Results from the Big Lung TrialRadiotherOncol. 2005;75(2):134-140

5. Perez et al. 1980 :patients with IIIA/IIIB treated with RT alone randomized to $2 / 40$ Gy vs. 2/50 Gy vs. 2/60 Gy vs. 4/40 Gy (split-course). RTOG 73-01

6. Blanke $\mathrm{C}$ : Phase III trial of thoracic irradiation with or without Cisplatin for locally advanced unresectable non-smallcell lung cancer: a Hoosier Oncology Group protocol , J ClinOncol. 1995 Jun;13(6):1425-9..

7. Trovo MG: Radiotherapy versus radiotherapy enhanced by Cisplatin in stage III non-small cell lung cancer , Int J Radiat Oncol Biol Phys. 1992;24(1):11-5.

8. Soresi E:A randomized clinical trial comparing radiation therapy $\mathrm{v}$ radiation therapy plus cis-dichlorodiammine platinum (II) in the treatment of locally advanced non-small cell lung cancer, Semin Oncol. 1988 Dec;15(6 Suppl 7):20-5.)

9. AuperinA:Meta-Analysis of Concomitant versus Sequential Radio chemotherapy in Locally Advanced Non-Small-Cell Lung Cancer , J ClinOncol 2010 May 1;28(13):2181-2190.

10. Exclusive Radiotherapy for Non Small Cell Lung Cancer. A Retrospective Multicentric Study-Received November 21st, 2002; received in a revised form March 24 th, 2003; accepted April 22th 2003. 
11. Clinical Lung Cancer, Vol. 12, No. 4, 24551 (C) 2011 Elsevier Inc]-2011 Jul;12(4): 245-51. doi: 10.1016/j.cllc.2011.03.026. Epub 2011 Apr 24. Acute esophagitis and late lung toxicity in concurrent chemoradiotherapy trials in patients with locally advanced non-small-cell lung cancer: analysis of the radiation therapy oncology group (RTOG) database.

12. Dillman RO etal; Improved survival in stage 111non-small cell lung cancer.Seven year follow up of CALBG 8433 trial,JNati Cancer Inst 88:1210-1215,1966

13. Sause WT, Scott C, Taylor S, et al: Radiation Therapy Oncology Group (RTOG) 88-08 and Eastern Cooperative Oncology Group (ECOG) 4588: Preliminary results of a phase III trial in regionally advanced unresectable nonsmall-cell lung cancer. J NatlCancerInst 87:198-205, 1995

14. Gervais R, Ducolone A, Lechevalier T, et al: Conventional radiation (RT) with daily carboplatin $(\mathrm{Cb})$ compared to RT alone after induction chemotherapy (ICT) [vinorelbine (Vr)-cisplatin (P)]: Final results of a randomized phase III trial in stage III unresectablenon small cell lung (NSCLC) cancer- Study CRG/BMS/ NPC/96 of the French Lung Cancer Study Group FNCLCC and IFCT. J ClinOncol 23:n625s, 2005 (suppl 16, abstr 7016)

15. Mote PA, Davey MW, Davey RA, et al: Paclitaxel sensitizes multidrug resistant cells to radiation. Anticancer Drugs 7:182188, 1996

16. Leonard CE, Chan DC, Chou TC, et al: Paclitaxel enhances in vitro radiosensitivity of squamous carcinoma cell lines of the head and neck. CancerRes 56:5198-5204, 1996

17. Rudolf M. Huber, Michael Flentje, Michael Schmidt, Barbara Pöllinger, Helga Gosse, Jochen Willner, and Kurt Ulm
Simultaneous

Chemoradiotherapy

Compared With Radiotherapy Alone After Induction Chemotherapy in Inoperable Stage IIIA or IIIB Non-Small-Cell Lung Cancer: StudyCTRT99/97 by the Bronchial Carcinoma Therapy Group JCO -Volume 24 _ Number 27 _ September 20 2006.

18. Kim TH, Dose-volumetric parameters for predicting severe radiation pneumonitis after three-dimensional conformal radiation therapy for lung cancer."

19. Lung Cancer ,vol.1 2012 by Dr. Purvish M. Parikh

20. Maintenance therapy in advanced nonsmall cell lung cancer: evolution, tolerability and outcomes-J.thoracic oncol.2010.may5(5) 723-34. 